\title{
Curie temperature of weakly shocked target basalts at the Lonar impact crater, India
}

\author{
A. Agarwal ${ }^{*}$ (I) and L. M. Alva-Valdivia²
}

\begin{abstract}
The study investigates Curie temperature $\left(T_{C}\right)$, bulk magnetic susceptibility, hysteresis, and X-ray diffraction pattern of in situ target basalts of Lonar impact crater, India. The main magnetic phase in the target basalt is low-Ti titanomagnetite. This study reveals an increase in $T_{C}$ and decrease in magnetic susceptibility and in full width at half maxima of the 311 peaks of titanomagnetite with distance from the crater center. Changes in crystal lattice of titanomagnetite, such as straining of 311 peaks, decrease in apparent crystallite size, and grain fragmentation may be among the possible reasons for the observed trends in $T_{C}$ and magnetic susceptibility. However, they both do not show any correlation between each other, indicating that different shock-induced processes affect them.
\end{abstract}

Keywords: Lonar impact crater, Variation in Curie temperature, Variation in bulk magnetic susceptibility, X-ray diffraction pattern

\section{Introduction}

Magnetite is a common ferrimagnetic mineral in the terrestrial and extraterrestrial rocks. Magnetite and other ferromagnetic minerals are a source of magnetic anomalies associated with terrestrial and extraterrestrial impact craters and, therefore, play an important role in their discovery and mapping (e.g., Pilkington and Grieve 1992; Plado et al. 1999; Gilder et al. 2018). Moreover, behavior of magnetite and other ferromagnetic minerals at various shock pressures has been used to identify the magnetic mineralogy of Mars (Louzada et al. 2011). Although critical for impact cratering research on Earth and elsewhere, the behavior of magnetite, in weakly shocked rocks, is not well understood.

Magnetite has a typical inverse spinel structure with $\mathrm{Fe}(\mathrm{II})$ and $\mathrm{Fe}(\mathrm{III})$ disordered in the octahedral sites and fully occupied tetrahedrons by $\mathrm{Fe}(\mathrm{III})$ cation (Verwey and Haayman 1941). At temperatures below Verwey transition $\left(T_{\mathrm{V}}\right)$, about $110-120 \mathrm{~K}$, magnetite has an orthorhombic crystal structure (Verwey and Haayman

\footnotetext{
*Correspondence: amar@daad-alumni.de

${ }^{1}$ Albert-Ludwigs-Universität Freiburg, Institut für Geo- und

Umweltnaturwissenschaften, Albertstraße 23b, 79104 Freiburg, Germany

Full list of author information is available at the end of the article
}

1941; Iizumi et al. 1982). At temperatures between $T_{V}$ and Curie temperature $-T_{\mathrm{C}}\left(\sim 856 \mathrm{~K}\right.$ or $\left.582.85{ }^{\circ} \mathrm{C}\right)$, it is cubic, and it is ferrimagnetic due to an anti-ferromagnetic coupling of $\mathrm{Fe}(\mathrm{III})$ in tetrahedral and octahedral sites and Fe(II) in octahedral sites (Néel 1948; Tarling and Hrouda 1993). Beyond $T_{\mathrm{C}}$, it is paramagnetic (Shull et al. 1951), due to the loss of magnetic ordering (Harrison and Putnis 1995, 1996).

Titanomagnetites form a solid-solution series $\left(\mathrm{Fe}_{3-x} \mathrm{Ti}_{x} \mathrm{O}_{4}\right)$ with magnetite $(0=x)$ and ulvöspinel $(x=1)$ as the two end members. The dependence of magnetite $T_{\mathrm{C}}$ upon the chemical composition is well established. There is a negative correlation between $T_{\mathrm{C}}$ and the ulvöspinel content, ' $x$ ' (e.g., Akimoto et al. 1957; Özdemir and O'Reilly 1981; Moskowitz et al. 1998; Lattard et al. 2006). This correlation is owed to the change in lattice parameters due to replacement of Fe cation by Ti (Akimoto et al. 1957).

Another factor affecting $T_{\mathrm{C}}$ is hydrostatic pressure. $T_{\mathrm{C}}$ of titanomagnetite, with ulvöspinel component from 0 to 0.7 , increases linearly with static pressures up to $6 \mathrm{GPa}$ (Samara and Giardini 1969; Schult 1970). Under hydrostatic pressure, a cubic crystal, such as that of magnetite, results in a cubic unit cell with decreased interionic distances (barring any phase transformation). 
This causes increased interionic exchange and higher $T_{\mathrm{C}}$ (Samara and Giardini 1969). However, a similar direct correlation between crystallographic changes and $T_{\mathrm{C}}$ due to dynamic shock pressure is not yet established. This may be partly owed to lack of sufficient experimental investigations and partly due to complex shock wave behavior (reflection and refraction) due to heterogeneity in rocks at natural craters. Shock waves from natural and experimental craters may indirectly affect $T_{\mathrm{C}}$ by fracturing the magnetic grains, thus facilitating hydrothermal alteration to increase the proportion of non-stoichiometric magnetite (Kontny et al. 2018). The grain fragmentation may also transform multi-domain magnetite (MD) to pseudo-single domain (PSD) or single domain (SD), thus reducing the magnetic susceptibility (e.g., Reznik et al. 2016).

This study investigates the variation in $T_{\mathrm{C}}$, magnetic susceptibility, and XRD pattern in the weakly shocked target basalts $(<3 \mathrm{GPa})$ of Lonar impact structure. The results show a systematic change in these properties with distance from the center of Lonar impact crater, i.e., with a change in peak shock pressure. To our knowledge, this is the first report of such correlation from weakly shocked rocks of a natural crater.

\section{Geological setting and rock magnetic properties}

Lonar crater $\left(19^{\circ} 58^{\prime} \mathrm{N}, 76^{\circ} 31^{\prime} \mathrm{E}\right)$ in the Buldana district of India is a hypervelocity impact crater excavated in the ca. 65 Ma tholeiitic Deccan basalt (Hagerty and Newsom 2003; Maloof et al. 2010). Some studies using fission track and thermoluminescence dating suggested that the Lonar impact occurred 50 ka (Fredriksson et al. 1973), while other reports using ${ }^{40} \mathrm{Ar} /{ }^{39} \mathrm{Ar}$ dating argue that the impact crater is ca. $570 \mathrm{ka}$ in age (Jourdan et al. 2011). The $\sim 1.88 \mathrm{~km}$ wide simple crater is $150 \mathrm{~m}$ deep from the rim and is filled with a 7-10-m-deep lake. The lake is filled with $30-100$-m-thick unconsolidated postimpact sediments, which are underlain by $225 \mathrm{~m}$ of impact breccia (Fredriksson et al. 1973; Fudali et al. 1980; Grieve et al. 1989). The Lonar crater is an excellent analog of extraterrestrial impact craters on basalt. It is relatively pristine and has not undergone any postimpact tectonism (Maloof et al. 2010; Agarwal et al. 2016).

The target basalt is comprised of five very similar and homogenous Deccan basalt flows (Fig. 1), whose

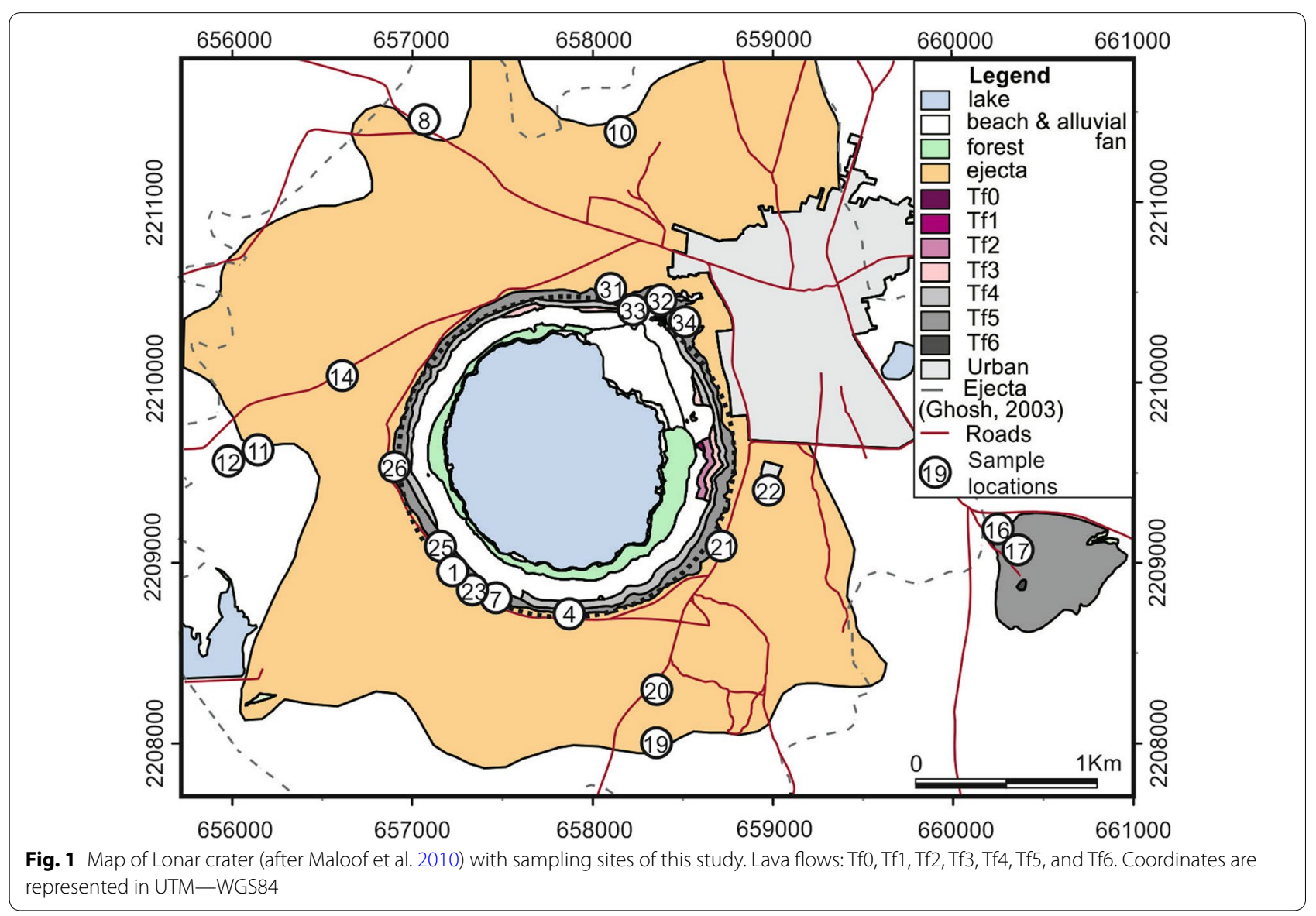


geochemical, textural, and rock magnetic properties have been studied in detail (e.g., Kieffer et al. 1976; Hagerty and Newsom 2003). The $\mathrm{TiO}_{2}$ content of different flows of the target basalt is similar (Osae et al. 2005). Each flow is $\sim 8$ to $40 \mathrm{~m}$ thick, separated by horizons of red and green paleosols and has vesicles filled with secondary materials like chlorite, zeolite, quartz, and brown limonite, and most have a chill margin at their bottom and a heated and brecciated top (Ghosh and Bhaduri 2003). The flows exposed in the Lonar crater wall are chemically similar and are classified as relatively low- $\mathrm{K}$ tholeiitic intra-plate basalts, with minor $\mathrm{Fe}$ and $\mathrm{Ca}$ enrichment and slight $\mathrm{Mg}$ and $\mathrm{Al}$ depletion compared to "average" tholeiites (Osae et al. 2005). All of the shocked basalts are altered, containing vesicles and veins full of carbonate and clays (Hagerty and Newsom 2003).

The alteration is recorded as young ( $<50 \mathrm{kya})$ viscous and/or chemical remanent magnetization in the target rocks (Louzada et al. 2008; Arif et al. 2012; Agarwal et al. 2016). The target basalts also present an older component similar to the Deccan direction (Louzada et al. 2008; Agarwal et al. 2016). The main magnetic phase in the target basalt is low-Ti titanomagnetite with a magnetic domain state ranging from single to multi-domain (Agarwal et al. 2016). The target basalts exposed around the crater rim have experienced shock pressures between 0.2 and $0.5 \mathrm{GPa}$ (Agarwal et al. 2016).

\section{Methodology}

Shocked basalts were collected from the Lonar impact structure, India. The magnetic mineralogy was first investigated under reflected light in an optical microscope. In total, 21 samples were analyzed for the variation of magnetic susceptibility with the temperature at the Institute of Applied Geosciences, Karlsruhe Institute of Technology, Karlsruhe, Germany. The variation in low-field magnetic susceptibility at low temperature was measured with Kappabridge (KLY-4S) equipped with CS-L cryostat. The sample was cooled to $-192^{\circ} \mathrm{C}$ using liquid nitrogen. Then the nitrogen was flushed out using a blast of argon, and the susceptibility was measured as the sample warmed to the room temperature. For high-temperature measurements, the Kappabridge (KLY-4S) was equipped with a CS-3 furnace. The sample was heated from room temperature up to $700{ }^{\circ} \mathrm{C}$ at a rate of $10{ }^{\circ} \mathrm{C} / \mathrm{min}$ and then cooled back. The bulk magnetic susceptibility was measured during the entire cycle of heating and cooling. Possible oxidation while heating was minimized by flushing out air from the sample holder using argon flowing at $50 \mathrm{ml} / \mathrm{min} . T_{\mathrm{C}}$ was calculated by two-tangent method (e.g., Petrovský and Kapička 2006). $T_{\mathrm{C}}$ s thus calculated were crosschecked with the first derivative method. Bulk magnetic susceptibility of each sample was measured at room temperature in the Kappabridge (KLY-4S).

Hysteresis curves were determined using Alternating Gradient Field Magnetometer Micromag apparatus in fields up to $1.4 \mathrm{~T}$. The curves allow calculating the remanence of coercivity-to-coercive force $(\mathrm{Hcr} / \mathrm{Hc})$ and the remanent magnetization-to-saturation remanence (Mrs/ Ms) ratios of each sample. These ratios are used to estimate the relative proportions of the single domain (SD), multi-domain (MD), and pseudo-single domain (PSD) grains (Dunlop 2002a, b). In general, the ratio of Mrs/ Ms is higher for more SD materials and lower for more MD-like materials. Agarwal et al. (2016) applied stepwise increasing uniaxial field on the samples to calculate the saturated and non-saturated isothermal remanent magnetization (IRM) acquisition curves. These curves were used to determine the median destructive field (MDF). The samples were then divided into magnetically hard, soft, and intermediate groups, based on the dominant magnetic domain state and the MDF.

The XRD pattern of magnetically hard basalts (dominated by SD) was measured with a Siemens D500 diffractometer using a $\mathrm{Cu}-\mathrm{Ka}$ anode. For each sample, the $2 \theta$ range $10^{\circ}-90^{\circ}$ was scanned with an angular speed of $0.5^{\circ} \%$ min. The variation in full width at half maxima (FWHM) of the 311 peaks with distance from the crater center is calculated. This peak was selected because it is the most intense peak of the magnetite diffraction spectra and has been a subject of previous investigations as well (e.g., Reznik et al. 2016). Diffraction peaks of (Ti-)magnetite can be broadened by the reduction in crystallite size or by introducing strain into the crystal lattice (e.g., Reznik et al. 2016). The apparent crystallite size is, therefore, calculated from FWHM of the X-ray diffraction peak using Scherrer's equation:

$$
D=k \lambda /(\beta \cos \theta),
$$

where $D$ is the crystal diameter, $k$ is the Scherrer's constant (0.9 for magnetite; El Ghandoor et al. 2012), $\lambda$ $(0.154056 \mathrm{~nm})$ is the X-ray wavelength, $\beta$ the FWHM of a diffraction peak in radians, 311 in our case, and $\theta$ is the diffraction angle in radians.

\section{Results}

\section{Magnetic mineralogy}

The basalt consists of phenocrysts of plagioclase (up to $1500 \mu \mathrm{m}$ ) in a fine-grained matrix of plagioclase (up to $60 \mu \mathrm{m}$,) pyroxene (up to $200 \mu \mathrm{m}$ ) and opaque phases (up to $100 \mu \mathrm{m}$ ). Reflected light microscopy reveals that most of the opaque phases are intergrown titanomagnetite and ilmenite (Fig. 3). Some grains of pyroxene and plagioclase are altered, along the fractures and grain boundaries to clay minerals. 

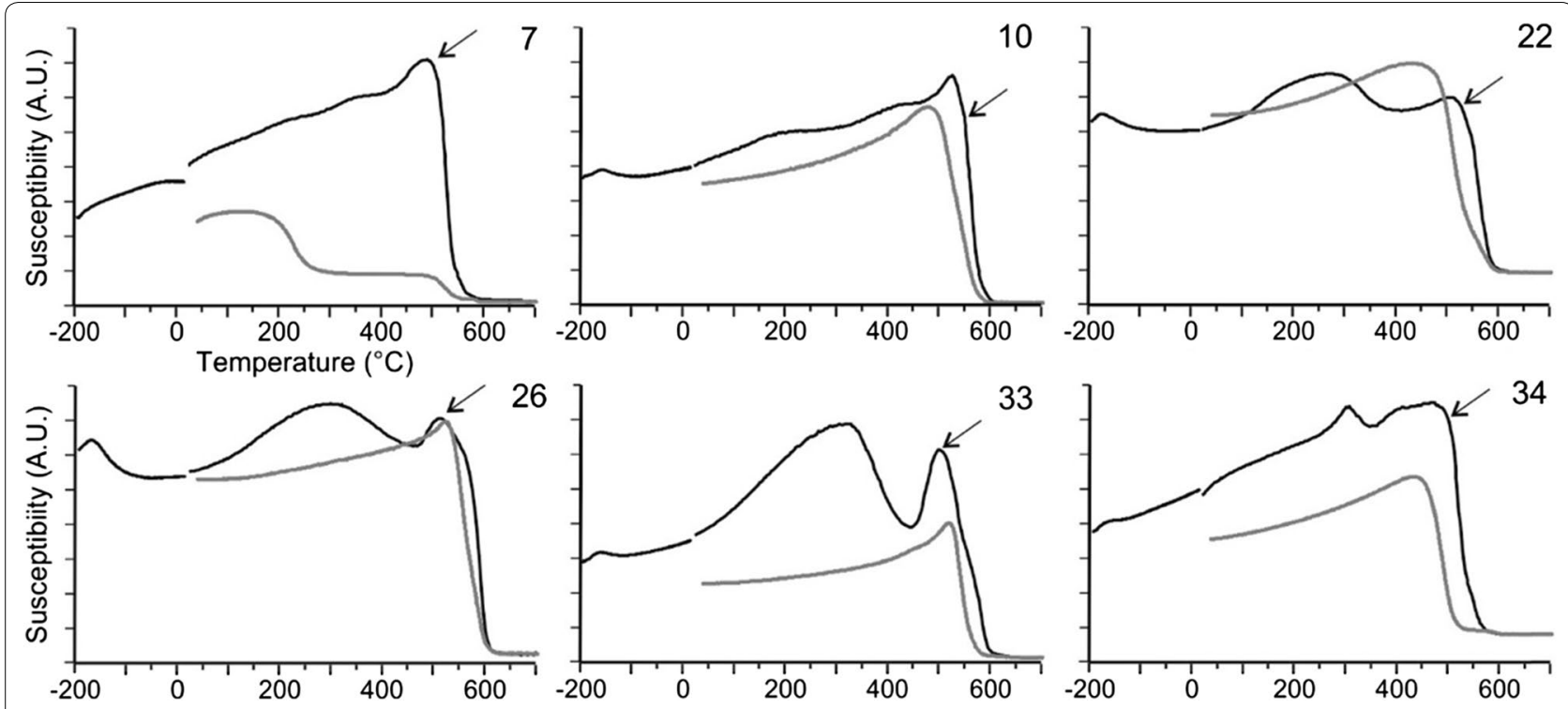

Fig. 2 Representative $x-T$ curves of the basalts showing the variation in magnetic susceptibility during heating (black) and cooling (gray). The higher $T_{C}$ is marked by a black arrow. AU arbitrary units
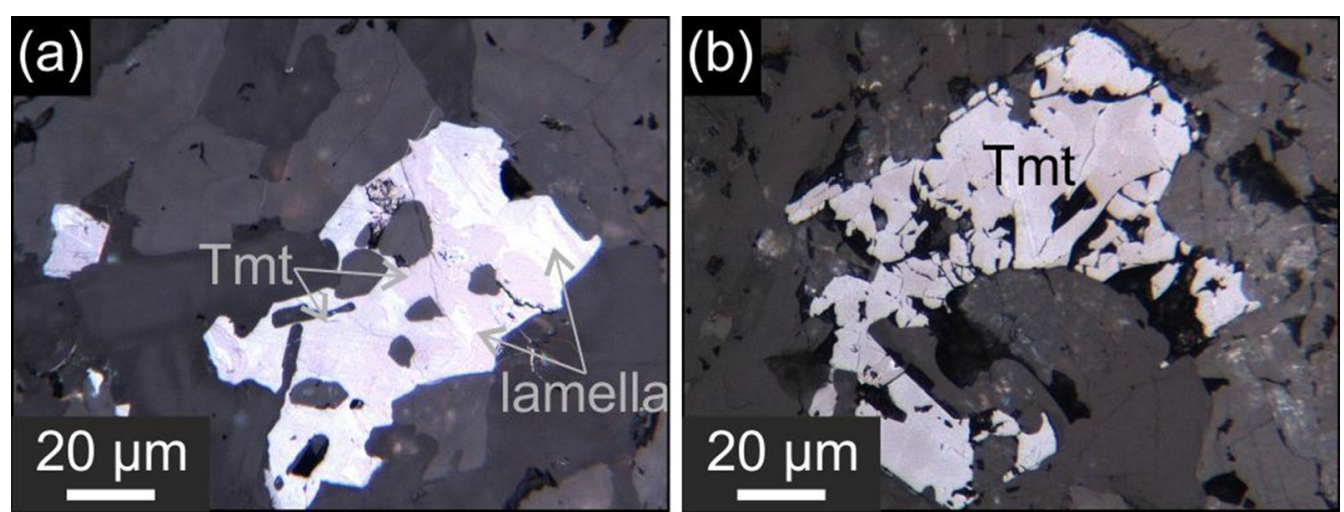

Fig. 3 Reflected light photomicrographs present a oxyexsolved Tmt grains with Ti-rich lamellae and $\mathbf{b}$ an optically homogeneous titanomagnetite (Tmt) grains

In the thermomagnetic curves, the Verwey transition peak is broad and subtle or completely absent, indicating a minor contribution of magnetite near end-member phase (Fig. 2). However, all curves show conspicuous $T_{\mathrm{C}}$ between 506 and $560{ }^{\circ} \mathrm{C}$ indicating the oxyexsolved Timagnetite grains with Ti-rich lamellae in a Ti-depleted host (e.g., Jackson and Bowles 2014), which is also supported by reflected light microscopic observation (Fig. 3a). A second $T_{C}$ is common in the heating branch between 300 and $450{ }^{\circ} \mathrm{C}$, possibly indicating Ti-maghemite (e.g., Moskowitz 1981). The curves are generally reversible over $500-550{ }^{\circ} \mathrm{C}$ (Fig. 2). In the cooling branch, the absence of the second $T_{\mathrm{C}}$ and lower susceptibility and the irreversibility below $500{ }^{\circ} \mathrm{C}$ are owed to the destruction of Ti-maghemite possibly into Ti-hematite at high temperatures (e.g., Alva-Valdivia et al. 2017, 2019).

The $\mathrm{Hcr} / \mathrm{Hc}$ ratio varies from 0.174 to 2.672 and the $\mathrm{Mrs} / \mathrm{Ms}$ ratio varies from 0.04 to 0.373 , indicating that the magnetic behavior in different samples is dominated by different domain states ranging from $\mathrm{SD}$ to MD. Depending upon the dominant magnetic domain state and the MDF of the remanence (varying from 6 to $61 \mathrm{mT}$ ), the target basalts were divided into three groups: (Group 1) thirteen samples dominated by SD and presenting a magnetically hard behavior with MDF > $22 \mathrm{mT}$; (Group 2) five magnetically soft samples dominated by MD with MDF $\leq 7 \mathrm{mT}$; and (Group 
3) three intermediate samples with a mixture of SD and $\mathrm{MD}$, and MDF between 8 and $21 \mathrm{mT}$.

\section{Shock effects}

The basalts of Group 1 (with high MDF and dominated by SD) show a clear increase in $T_{\mathrm{C}}$ with distance from the crater center, i.e., decreasing shock pressure (Fig. 4). Notably, $T_{\mathrm{C}}$ increases from $475.6^{\circ} \mathrm{C}$ to $562{ }^{\circ} \mathrm{C}$ almost linearly. Basalts of Group 2 and 3 show a similar increase in $T_{\mathrm{C}}$ with distance from the crater center (Additional file 1: Figure S1). However, due to fewer samples (5 and
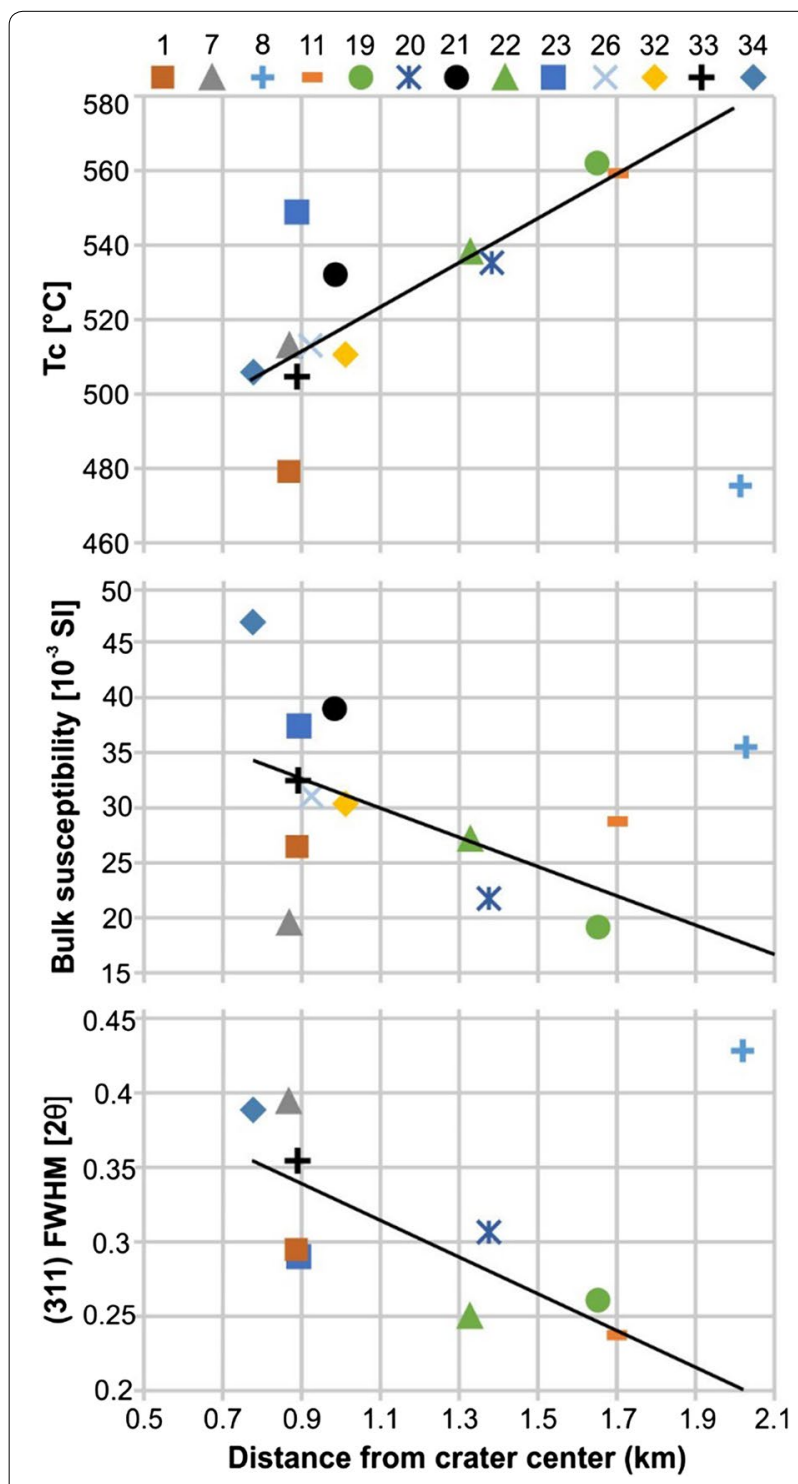

Fig. 4 Variation in $T_{C}$, bulk magnetic susceptibility and FWHM with the distance from the crater center. Note that the black trend line is calculated by excluding sample 8
3 , respectively) and statistically unreliable trend, they are excluded from further investigations.

Contrary to this trend of $T_{\mathrm{C}}$, the bulk magnetic susceptibility and the FWHM of the group 1 basalt decrease with distance from the crater center (Fig. 4). The bulk magnetic susceptibility decreases from $75.3 \times 10^{-3}$ SI to $46.8 \times 10^{-3} \mathrm{SI}$, while the $2 \theta$ of the FWHM decreases from $0.43^{\circ}$ to $0.24^{\circ}$ (Table 1 ). The apparent crystal diameter ' $D$ ' increases with distance from the crater center in accordance with the FWHM. For sample 34, nearest to the crater center, $D$ is $21.53 \mathrm{~nm}$, while for sample 11, which is farthest from the crater center, $D$ is $35.38 \mathrm{~nm}$ (Table 1).

Note that, sample 8, collected from the north of the Lonar crater, it is farthest from the crater, but presents the least $T_{\mathrm{C}}\left(475.6{ }^{\circ} \mathrm{C}\right)$. This sample is an outlier to all these trends and is excluded during calculating the trend line and from further discussion.

\section{Discussion}

The study reports magnetic mineralogy, bulk magnetic susceptibility and the XRD pattern of shocked basalts from the Lonar impact structure, India. In the shocked basalts, $T_{\mathrm{C}}$ decreases but the FWHM of the 311 peak and bulk magnetic susceptibility increase with vicinity to the crater center, i.e., with increasing shock pressures (Fig. 4, Additional file 1: Fig. S1).

The increase in FWHM with vicinity to the crater center may be owed to increasing strain in the crystal lattice, due to anisotropic compression by shock waves, and to decreasing apparent crystallite size (e.g., Reznik et al. 2016). The crystallite size of shocked magnetite reported here for Lonar basalts $(21.3-35.38 \mathrm{~nm})$ is smaller than the size $(80-180 \mathrm{~nm})$ reported by Reznik et al. (2016). This difference may be due to the fact that the starting material for Reznik et al. (2016) was of the banded magnetite-quartz ore with larger unshocked crystals, whereas in Lonar basalts, magnetite is an accessory mineral with smaller crystals.

\section{Variation in bulk magnetic susceptibility}

The target basalts at Lonar impact structure present an increase in bulk susceptibility with increasing shock pressure. On the one hand, these trends disagree with the effects of static pressures up to $0.6 \mathrm{GPa}$, which decrease the bulk magnetic susceptibility (Kapička 1988). The decrease is owed to significant isomer shifts that octahedral lattices of magnetite undergo up to $5 \mathrm{GPa}$ (Halasa et al. 1974), and to linear volume decrease possibly causing anisotropic compression, thus influencing the magnetic lattice network via changes in magnetostriction and magnetocrystalline constants (Nagata and Kinoshita 1967; Gilder et al. 2004). 
Table 1 Table compiles the distance of each sample from the crater center; apparent crystallite size is $(D)$; bulk magnetic susceptibility $(x)$; Curie temperature $\left(T_{c}\right)$; the ratios: remanence of coercivity to coercive force $(\mathrm{Hcr} / \mathrm{Hc})$ and the remanent magnetization to saturation remanence (Mrs/Ms)

\begin{tabular}{|c|c|c|c|c|c|c|c|c|c|}
\hline Sample & Distance (km) & FWHM $2 \theta\left(^{\circ}\right)$ & $D(\mathrm{~nm})$ & $x\left(10^{-3} \mathrm{SI}\right)$ & $T_{\mathrm{C}}\left({ }^{\circ} \mathrm{C}\right)$ & $\mathrm{Hcr} / \mathrm{Hc}$ & Mrs/Ms & MDF (mT) & Coercivity \\
\hline 34 & 0.776 & 0.39 & 21.53 & 46.8 & 505.8 & 2.066 & 0.207 & 38 & High \\
\hline 25 & 0.851 & - & - & 50.7 & 517.4 & 1.365 & 0.151 & 12 & Medium \\
\hline 7 & 0.868 & 0.39 & 21.23 & 19.6 & 506.5 & 1.594 & 0.235 & 22 & High \\
\hline 4 & 0.884 & & - & 44.4 & 461.6 & 2.327 & 0.107 & 8 & Low \\
\hline 1 & 0.888 & 0.29 & 28.47 & 26.5 & 479 & 1.414 & 0.178 & 25 & High \\
\hline 33 & 0.891 & 0.35 & 23.74 & 32.5 & 504.8 & 2.156 & 0.19 & 44 & High \\
\hline 23 & 0.893 & 0.29 & 28.85 & 37.4 & 548.6 & 1.702 & 0.302 & 28 & High \\
\hline 26 & 0.925 & - & - & 31.1 & 513.1 & 2.124 & 0.207 & 50 & High \\
\hline 31 & 0.96 & - & - & 53.1 & 537.8 & 2.352 & 0.202 & 9 & Medium \\
\hline 21 & 0.984 & - & - & 39 & 532.5 & 2.523 & 0.133 & 30 & High \\
\hline 32 & 1.011 & - & - & 30.4 & 510.6 & 2.106 & 0.221 & 31 & High \\
\hline 14 & 1.321 & - & - & 61.7 & 498 & 1.241 & 0.146 & 8 & Low \\
\hline 22 & 1.328 & 0.25 & 33.45 & 27.2 & 538.3 & 1.057 & 0.373 & 31 & High \\
\hline 20 & 1.375 & 0.30 & 27.35 & 21.8 & 535.6 & 1.201 & 0.04 & 58 & High \\
\hline 19 & 1.652 & 0.26 & 32.16 & 19.2 & 562 & 1.62 & 0.138 & 50 & High \\
\hline 11 & 1.702 & 0.24 & 35.38 & 28.8 & 559 & 2.011 & 0.204 & 61 & High \\
\hline 12 & 1.702 & - & - & 48.8 & 525.5 & 1.257 & 0.173 & 8 & Low \\
\hline 10 & 1.818 & - & - & 75.3 & 552.5 & 0.174 & 0.17 & 9 & Medium \\
\hline 8 & 2.019 & 0.43 & 19.60 & 35.5 & 475.6 & 1.293 & 0.171 & 28 & High \\
\hline 16 & 2.413 & - & - & 73.1 & 536.6 & 0.388 & 0.259 & 8 & Low \\
\hline 17 & 2.542 & - & - & 59.7 & 521.3 & 2.672 & 0.086 & 6 & Low \\
\hline
\end{tabular}

The median destructive field (MDF) and the coercivity estimates are taken from Agarwal et al. (2016)

On the other hand, present observations agree with the trends in cratering experiments. Here experimental shock pressure $(<3 \mathrm{GPa})$ increases the bulk magnetic susceptibility of rocks with small magnetite grains, $<10 \mu \mathrm{m}$ (Agarwal et al. 2019). Although the mechanism behind this increase is not known, their results agree well with the present observations. In contrast, at higher shock pressures (3-20 GPa), bulk magnetic susceptibility decreases due to damage in the crystal lattice and grain fragmentation causing MD magnetite to break into PSD and SD magnetite (Nishioka et al. 2007; Louzada et al. 2010; Reznik et al. 2016, 2017). A decrease in magnetic susceptibility is also reported from the drill cores of the El'gygytgyn impact structure but is owed to impactrelated hydrothermal alteration (Kontny and Grothaus 2017)

\section{Variation in Curie temperature}

The decrease in $T_{\mathrm{C}}$ with increasing shock pressure in Lonar basalts is in contrast to the effects of static pressure. For example, static pressures up to $5 \mathrm{GPa}$ are known to increase $T_{\mathrm{C}}$ (Schult 1970). The changes in the crystal lattice by shock waves may affect the $T_{\mathrm{C}}$. However, no other natural and experimental studies have investigated the effect of dynamic pressures on $T_{\mathrm{C}}$ and therefore a comparison is not possible.

Notably, changes in $T_{\mathrm{C}}$ and magnetic susceptibility due to formation of new magnetite (by hydrothermal alteration or some other process) may be precluded because paleomagnetic investigations reveal a single high coercivity component, which is associated with the emplacement of the basalts (Louzada et al. 2008; Agarwal et al. 2016). The scatter in the trends of $T_{C}$ and magnetic susceptibility (Fig. 4) could be related to slight variation in magnetic mineralogy that predates impact or could arise from heterogeneity in the pressure field at the time of impact.

\section{Conclusions}

Until now, the shock demagnetization of magnetic minerals such as magnetite, Ti-magnetite, hematite, Ti-hematite, and pyrrhotite (see Louzada et al. 2011 and the references therein) was the only effect of low shock pressures $(<3 \mathrm{GPa})$, which was considered of importance at a regional scale. However, now, increase in magnetic susceptibility of Ti-magnetite, at low shock pressures, is clear from present investigations 
on naturally shocked target basalts at Lonar impact structure, and from experiments (Agarwal et al. 2019). As most of the target rocks in the crater subsurface are generally weakly shocked, $<3$ GPa (Pierazzo and Melosh 2000; Kenkmann et al. 2014), such an increase in magnetic susceptibility will affect the induced magnetization, thus, changing the magnetic anomalies at these impact structures.

While there are no other studies on the $T_{\mathrm{C}}$ of weakly shocked rocks, there is only one study on magnetic susceptibility, which shows its increase with shock pressures below $3 \mathrm{GPa}$, without commenting on the mechanism (e.g., Agarwal et al. 2019). Changes in the crystal lattice, such as straining of (311) peak, decrease in apparent crystallite size, and grain fragmentation may be among the possible reasons for one of the observed trends in $T_{\mathrm{C}}$ and magnetic susceptibility. However, they both do not show any correlation between each other, indicating that different shockinduced processes affect them.

Moreover, the deformation under static and dynamic condition is fundamentally different because of phenomenon like strain hardening (Simpson 1985). Studies on the effects of experimental and natural static pressures, therefore, cannot directly be used to interpret the effects of dynamic shock waves. The present data set reveals systematic changes in $T_{\mathrm{C}}$ and magnetic susceptibility with shock pressures below $3 \mathrm{GPa}$. However, the present data do not pin down the precise mechanism behind these changes. Further experimental investigations, in controlled settings, which link rock magnetic changes with crystallographic effects at low shock pressures are needed to identify the active processes.

\section{Supplementary information}

Supplementary information accompanies this paper at https://doi. org/10.1186/s40623-019-1120-9.

Additional file 1: Figure S1. Variation in Curie temperature with the distance from the crater center for Group 2 (Low coercivity-Soft) and Group 3 (Intermediate coercivity) samples.

\section{Acknowledgements}

Phillip Lied measured the thermomagnetic curves. Prof. A. Kontny is thanked for access to the Kappabridge. We thank two anonymous reviewers for their helpful constructive criticism and the editors for their guidance during the review process.

\section{Authors' contributions}

AA collected the samples and interpreted the thermomagnetic and XRD results. LM measured and interpreted hysteresis. Both authors read and approved the final manuscript.

\section{Funding}

The fieldwork was funded by Deutscher Akademischer Austauschdienst (A/11/76052) and by Innovationsfonds 2017 Uni Freiburg. AA holds the Alexander von Humboldt Post-Doctoral Fellowship.

\section{Availability of data and materials}

All of the data on which this manuscript is based are provided in the main text.

\section{Competing interests}

The authors declare that they have no competing interests.

\section{Author details}

${ }^{1}$ Albert-Ludwigs-Universität Freiburg, Institut für Geo- und Umweltnaturwissenschaften, Albertstraße 23b, 79104 Freiburg, Germany. ${ }^{2}$ Laboratorio de Paleomagnetismo, Universidad Nacional Autónoma de México: Instituto de Geofísica, Ciudad Universitaria, 04510 Ciudad de México, Mexico.

Received: 10 September 2019 Accepted: 6 December 2019

Published online: 21 December 2019

\section{References}

Agarwal A, Kontny A, Srivastava DC, Greiling RO (2016) Shock pressure estimates in target basalts of a pristine crater: a case study in the Lonar crater, India. Geol Soc Am Bull 128(B31172):1. https://doi.org/10.1130/B31172.1

Agarwal A, Kontny A, Kenkmann T, Poelchau MH (2019) Variation in magnetic fabrics at low shock pressure due to experimental impact cratering. J Geophys Res Solid Earth. https://doi.org/10.1029/2018jb017128

Akimoto S, Katsura T, Yoshida M (1957) Magnetic properties of TiFe $\mathrm{O}_{4}-\mathrm{Fe}_{3} \mathrm{O}_{4}$ system and their change with oxidation. J Geomagn Geoelectr 9:165-178

Alva-Valdivia LM, Agarwal A, Caballero-Miranda C et al (2017) Paleomagnetic and AMS studies of the El Castillo ignimbrite, central-east Mexico: source and rock magnetic nature. J Volcanol Geotherm Res 336:140-154. https:// doi.org/10.1016/j.jvolgeores.2017.02.014

Alva-Valdivia LM, Agarwal A, García-Amador B et al (2019) Paleomagnetism and tectonics from the late Pliocene to late Pleistocene in the Xalapa monogenetic volcanic field. GSA Bull, Veracruz. https://doi.org/10.1130/ B32006.1

Arif M, Basavaiah N, Misra S, Deenadayalan K (2012) Variations in magnetic properties of target basalts with the direction of asteroid impact: example from Lonar crater, India. Meteorit Planet Sci 47:1305-1323. https://doi. org/10.1111/j.1945-5100.2012.01395.x

Dunlop DJ (2002a) Theory and application of the Day plot (Mrs/Ms versus Hcr/ Hc) 1. Theoretical curves and tests using titanomagnetite data. J Geophys Res 107:2056. https://doi.org/10.1029/2001jb000486

Dunlop DJ (2002b) Theory and application of the Day plot (Mrs/Ms versus $\mathrm{Hcr}$ / Hc) 2. Application to data for rocks, sediments, and soils. J Geophys Res 107:2057. https://doi.org/10.1029/2001jb000487

El Ghandoor H, Zidan HM, Khalil MMH, Ismail MIM (2012) Synthesis and some physical properties of magnetite $\left(\mathrm{Fe}_{3} \mathrm{O}_{4}\right)$ nanoparticles. Int J Electrochem Sci 7:5734-5745

Fredriksson K, Dube A, Milton DJ, Balasundaram MS (1973) Lonar lake, India: an impact crater in basalt. Science 180:862-864. https://doi.org/10.1126/ science.180.4088.862

Fudali RF, Milton DJ, Fredriksson K, Dube A (1980) Morphology of Lonar Crater, India: comparisons and implications. Moon Planets 23:493-515. https:// doi.org/10.1007/BF00897591

Ghosh S, Bhaduri SK (2003) Petrography and petrochemistry of impact melts from Lonar Crater. Buldana Dist Maharashtra India Indian Min 57:1-26

Gilder SA, LeGoff M, Chervin J-C, Peyronneau J (2004) Magnetic properties of single and multi-domain magnetite under pressures from 0 to $6 \mathrm{GPa}$. Geophys Res Lett. https://doi.org/10.1029/2004GL019844

Gilder SA, Pohl J, Eitel M (2018) Magnetic signatures of terrestrial meteorite impact craters: a summary. In: Lühr H, Wicht J, Gilder SA, Holschneider M (eds) Magnetic fields in the solar system. Springer, Cham, pp 357-382

Grieve RAF, Coderre JM, Rupert J et al (1989) Test of a geometric model for the modification stage of simple impact crater development. Meteoritics 88:83-88. https://doi.org/10.1111/j.1945-5100.1989.tb00948.x

Hagerty J, Newsom H (2003) Hydrothermal alteration at the Lonar Lake impact structure, India: implications for impact cratering on Mars. Meteorit Planet Sci 381:365-381

Halasa NA, Depasquali G, Drickamer HG (1974) High-pressure studies on ferrites. Phys Rev B 10:154-164. https://doi.org/10.1103/PhysRevB.10.154 
Harrison RJ, Putnis A (1995) Magnetic properties of the magnetite-spinel solid solution: saturation magnetization and cation distributions. Am Mineral 80:213-221

Harrison RJ, Putnis A (1996) Magnetic properties of the magnetite-spinel solid solution: Curie temperatures, magnetic susceptibilities, and cation ordering. Am Mineral 81:375-384. https://doi.org/10.2138/am-1996-3-412

lizumi M, Koetzle TF, Shirane $\mathrm{G}$ et al (1982) Structure of magnetite $\left(\mathrm{Fe}_{3} \mathrm{O}_{4}\right)$ below the Verwey transition temperature. Acta Crystallogr Sect B 38:2121-2133. https://doi.org/10.1107/S0567740882008176

Jackson M, Bowles JA (2014) Curie temperatures of titanomagnetite in ignimbrites: effects of emplacement temperatures, cooling rates, exsolution, and cation ordering. Geochem Geophys Geosyst 15:4343-4368. https:// doi.org/10.1002/2014GC005527

Jourdan F, Moynier F, Koeberl C, Eroglu S (2011) 40Ar/39Ar age of the Lonar crater and consequence for the geochronology of planetary impacts. Geology 39:671-674

Kapička A (1988) Anisotropy of magnetic susceptibility in a weak magnetic field induced by stress. Phys Earth Planet Inter 51:349-354. https://doi. org/10.1016/0031-9201(88)90075-1

Kenkmann T, Poelchau MH, Wulf G (2014) Structural geology of impact craters. J Struct Geol 62:156-182. https://doi.org/10.1016/j.jsg.2014.01.015

Kieffer SW, Schaal RB, Gibbons R, et al (1976) Shocked basalt from Lonar impact crater, India, and experimental analogues. In: Lunar and planetary science conference proceedings. pp 1391-1412

Kontny A, Grothaus L (2017) Effects of shock pressure and temperature on titanomagnetite from ICDP cores and target rocks of the El'gygytgyn impact structure, Russia. Stud Geophys Geod 61:162-183. https://doi. org/10.1007/s11200-016-0819-3

Kontny A, Reznik B, Boubnov A et al (2018) Postshock thermally induced transformations in experimentally shocked magnetite. Geochem Geophys Geosyst 19:921-931. https://doi.org/10.1002/2017GC007331

Lattard D, Engelmann R, Kontny A, Sauerzapf U (2006) Curie temperatures of synthetic titanomagnetites in the Fe-Ti-O system: effects of composition, crystal chemistry, and thermomagnetic methods. J Geophys Res 111:S28. https://doi.org/10.1029/2006jb004591

Louzada KL, Weiss BP, Maloof AC et al (2008) Paleomagnetism of Lonar impact crater, India. Earth Planet Sci Lett 275:308-319. https://doi.org/10.1016/j. epsl.2008.08.025

Louzada KL, Stewart ST, Weiss BP et al (2010) Shock and static pressure demagnetization of pyrrhotite and implications for the Martian crust. Earth Planet Sci Lett 290:90-101. https://doi.org/10.1016/j.epsl.2009.12.006

Louzada KL, Stewart ST, Weiss BP et al (2011) Impact demagnetization of the Martian crust: current knowledge and future directions. Earth Planet Sci Lett 305:257-269. https://doi.org/10.1016/j.epsl.2011.03.013

Maloof AC, Stewart ST, Weiss BP et al (2010) Geology of Lonar Crater, India. Geol Soc Am Bull 122:109-126. https://doi.org/10.1130/B26474.1

Moskowitz BM (1981) Methods for estimating Curie temperatures of titanomaghemites from experimental Js-T data. Earth Planet Sci Lett 53:84-88. https://doi.org/10.1016/0012-821X(81)90028-5

Moskowitz B, Jackson M, Kissel C (1998) Low-temperature magnetic behavior of titanomagnetites. Earth Planet Sci Lett 157:141-149

Nagata T, Kinoshita H (1967) Effect of hydrostatic pressure on magnetostriction and magnetocrystalline anisotropy of magnetite. Phys Earth Planet Inter 1:44-48. https://doi.org/10.1016/0031-9201(67)90007-6
Néel L (1948) Proprietes magnetiques des ferrites-ferrimagnetisme et antiferromagnetisme. Ann Phys (Paris) 3:137-198

Nishioka I, Funaki M, Sekine T (2007) Shock-induced anisotropy of magnetic susceptibility: impact experiment on basaltic andesite. Earth Planets Space 59:45-48. https://doi.org/10.1186/BF03352060

Osae S, Misra S, Koeberl C et al (2005) Target rocks, impact glasses, and melt rocks from the Lonar impact crater, India: petrography and geochemistry. Meteorit Planet Sci 40:1473-1492. https://doi. org/10.1111/j.1945-5100.2005.tb00413.x

Özdemir Ö, O'Reilly W (1981) High-temperature hysteresis and other magnetic properties of synthetic monodomain titanomagnetites. Phys Earth Planet Inter 25:406-418. https://doi.org/10.1016/0031-9201(81)90052-2

Petrovský ED, Kapička A (2006) On determination of the Curie point from thermomagnetic curves. J Geophys Res Solid Earth. https://doi. org/10.1029/2006jb004507

Pierazzo E, Melosh HJ (2000) Understanding oblique impacts from experiments, observations, and modeling. Annu Rev Earth Planet Sci 28:141167. https://doi.org/10.1146/annurev.earth.28.1.141

Pilkington M, Grieve RAF (1992) The geophysical signature of terrestrial impact craters. Rev Geophys 30:161. https://doi.org/10.1029/92RG00192

Plado J, Pesonen LJ, Puura V (1999) Effect of erosion on gravity and magnetic signatures of complex impact structures: geophysical modeling and applications. In: Special paper 339: large meteorite impacts and planetary evolution; II. Geological Society of America, pp 229-239

Reznik B, Kontny A, Fritz J, Gerhards U (2016) Shock-induced deformation phenomena in magnetite and their consequences on magnetic properties. Geochem Geophys Geosyst 17:2374-2393. https://doi. org/10.1002/2016GC006338

Reznik B, Kontny A, Fritz J (2017) Effect of moderate shock waves on magnetic susceptibility and microstructure of a magnetite-bearing ore. Meteorit Planet Sci 52:1495-1504. https://doi.org/10.1111/maps.12787

Samara GA, Giardini AA (1969) Effect of pressure on the Néel temperature of magnetite. Phys Rev 186:577-580. https://doi.org/10.1103/PhysR ev.186.577

Schult A (1970) Effect of pressure on the Curie temperature of titanomagnetites $\left[(1-\mathrm{x}) \cdot \mathrm{Fe}_{3} \mathrm{O}_{4}-\mathrm{x} \cdot \mathrm{TiFe}_{2} \mathrm{O}_{4}\right]$. Earth Planet Sci Lett 10:81-86. https://doi. org/10.1016/0012-821X(70)90067-1

Shull CG, Wollan EO, Koehler WC (1951) Neutron scattering and polarization by ferromagnetic materials. Phys Rev 84:912-921. https://doi.org/10.1103/ PhysRev.84.912

Simpson C (1985) Deformation of granitic rocks across the brittle-ductile transition. J Struct Geol 7:503-511

Tarling D, Hrouda F (1993) Magnetic anisotropy of rocks. Chapman \& Hall, London

Verwey EJW, Haayman PW (1941) Electronic conductivity and transition point of magnetite ('Fe3O4'). Physica 8:979-987. https://doi.org/10.1016/S0031 $-8914(41) 80005-6$

\section{Publisher's Note}

Springer Nature remains neutral with regard to jurisdictional claims in published maps and institutional affiliations.

\section{Submit your manuscript to a SpringerOpen ${ }^{\circ}$ journal and benefit from:}

- Convenient online submission

- Rigorous peer review

- Open access: articles freely available online

- High visibility within the field

Retaining the copyright to your article

Submit your next manuscript at springeropen.com 